Marx, C. M., Müller, K. W., \& Beutel, M. E. (2021). Adverse childhood experiences in persons with excessive and destructive online behaviour. Cyberpsychology: Journal of Psychosocial Research on Cyberspace, 15(3), Article 5. https://doi.org/10.5817/CP2021-3-5

\title{
Adverse Childhood Experiences in Persons With Excessive and Destructive Online Behaviour
}

\author{
Caroline M. Marx, Kai W. Müller, \& Manfred E. Beutel
}

Department of Psychosomatic Medicine and Psychotherapy, University Medical Center Mainz, Mainz, Germany

\begin{abstract}
Despite the widespread use of online sexual material in the general population, the overlap of deviant use of online sexual material (child sexual abusive material) with other types of online sex and gaming addictions has remained controversial. The purpose of this study is to determine, how users of child sexual abusive material (CSAM) differ from persons consulting for problematic online sex and for gaming (sociodemographic details, Internet use patterns, adverse childhood experiences). We assessed online addiction criteria and adverse childhood experiences in 479 consecutive patients (57 CSAM, 67 users of online sexual material, 355 online gamers) by standardized selfreport questionnaires (AICA, CTS). Patients presenting with CSAM consumption were well-educated, socially and professionally integrated middle-aged men. While the quantity of Internet use was less excessive compared to users of online sexual material and online gamers, their average online use was mostly addictive and disruptive regarding partnership or family. They reported significantly higher rates of own experiences of sexual childhood abuse and emotional neglect compared to gamers. Better understanding of CSAM consumption in the context of online addictions is a prerequisite for developing specific therapeutic approaches. These need to consider addictive behavior as well as sustained childhood adversities, which might lead to these maladaptive coping strategies.
\end{abstract}

Keywords: Online sex; child sexual abusive material; gaming; childhood maltreatment; behavioral addiction

\section{Introduction}

The Internet is characterized by constant availability, accessibility, affordability and anonymity, which offer innumerable opportunities to consume, distribute and communicate all kinds of sexual materials. The overlap of deviant use of online sexual material (CSAM) with other types of online activities (e.g., online sexual material, gaming) is increasingly discussed. As Internet -based surveys have shown, sexual offers have become highly attractive to a substantial proportion of Internet users. In a representative population survey (Beutel et al., 2011) male Internet users reported online sex use 4 times more often (21.5\%) than women (4.7\%); young men (below 34 years) were the most frequent users. In a US survey, $36.7 \%$ of adults reported consuming online sexual material, the majority (78\%) were male (Weaver et al., 2011). In a Swedish Internet sample $(N=1.913), 5 \%$ of the women reported some ( $2 \%$ serious) and $13 \%$ of the men reported some ( $5 \%$ serious) problems regarding online sex (loss of control, dysphoria, addictive tendencies, need for treatment; Ross et al., 2012).

Along with this proliferation of online pornography use (including any online sexual material e.g., pictures, videos, texts), there has been increasing concern about the spread of images or videos of sexual abuse of children.

According to the Terminology Guidelines for the Protection of Children from Sexual exploitation and Sexual Abuse (Terminology and Semantics Interagency Working Group on Sexual Exploitation of Children, 2016): The term "child 
sexual abuse material" or "child sexual exploitation material" is increasingly being used to replace the term "child pornography". The term "child pornography" has been considered inappropriate because pornography is a term used for adults engaging in consensual sexual acts distributed legally to the general public for their sexual pleasure. In contrast, sexual material implying a clear sexualisation of the child or acts of abuse, is a form of child sexual abuse, and should not be described as "pornography". Therefore, in the following the term "Child sexual abusive material" (CSAM) is used.

In 2017, 132,636 reports were processed by the Internet Watch Foundation analyst (Internet Watch Foundation, 2017), which was a $26 \%$ increase compared to 2016 (105,420 reports). A total of 80,319 reports were confirmed as containing criminal content. Furthermore, it was recorded that more than 3000 domains were containing pictures or videos of sexually exploited children (+57\% compared to 2016; (Internet Watch Foundation, 2017); Accessed June 6,2020$)$. In 2016, 5687 cases of possession and distribution of CSAM material were registered in Germany (Bundeskriminalamt, 2016). The estimated number of unknown cases is much higher (Beier et al., 2006; National Center for Injury Prevention and Control, 2018). Perceived anonymity and the "playful" nature of online environments may exert a disinhibiting effect on the user (Elliott \& Beech, 2009), along with the normalization and objectification of images as a commodity to be collected. In searching for new and increasingly exciting material, there is a strong likelihood of encountering illegal material (reported by $10.5 \%$ of the men and $3.1 \%$ of the women; (Beutel et al., 2017). It is not known, however, if CSAM consumers have similar demographic characteristics as other users of online sexual material.

The prevalence of pedophilic disorder, defined as lasting or recurrent intense sexual fantasies, urges or behaviors regarding sexual activity with prepubescent children, having acted on or being distressed about these urges, has been estimated between 1 to 5\% of the male population (Ahlers et al., 2011; American Psychiatric Association, 2013; Dombert et al., 2016). As shown by surveys (e.g., Briere \& Runtz, 1989; Hall et al., 1995) about $21 \%$ of males not known or self-labelled as pedophiles have reported deviant sexual fantasies regarding children. In an online sample of male pornography users, 21\% reported consuming CSAM (Ray et al., 2014); on the other hand, nonpedophile pornography was also discovered on the computers of CSAM offenders (of whom only 8\% were characterized as non -pedophile; (Niveau, 2010). In a recent online study with both sexes (Wurtele et al., 2014), 6\% of the men and $2 \%$ of the women reported some likelihood of having sex with a child (if they would not be caught or punished), and $9 \%$ of the men (2\% of the women) indicated some likelihood of viewing CSAM on the Internet. Sexual interest in children was associated with a higher subjective likelihood in engaging in other types of antisocial behavior and more dysfunctional childhood (e.g., sexual abuse, insecure attachment to parents). In a comprehensive meta-analysis (Babchishin et al., 2011) examining demographic and psychological variables in the group of online CSAM users and offline child sexual offenders (mostly identified by convictions what might limit the representativity of these groups), it was found that online offenders tend to be Caucasian males who are younger than the general population. Further, they did not differ from the general population in terms of education but were more often unemployed (Babchishin et al., 2011). Compared with offline offenders, it was shown that, online offenders had greater victim empathy and fewer cognitive distortions and less emotional identification with children (Babchishin et al., 2011). However, online offenders were shown to have greater sexual deviancy (Babchishin et al., 2011). It is discussed that this finding might be biased by the police activities in so far that the police might tend to charge only online offenders consuming CSAM where children are portrayed obviously physically immature and hence selectively charged online offenders who were more likely to have pedophiliac interests (Babchishin et al., 2011). Furthermore, online offenders tend to have higher levels of self control and less impulsivity which might restrain them from offending "offline" (Babchishin et al., 2011). Shame, fear of judgment or conviction may be further motives of not acting out their sexual preference offline.

Yet, little is known about the relation between CSAM consumption and Internet related disorders. From our clinical impression, a considerable proportion of CSAM users also showed symptoms of Internet related disorders. This notion was supported by Seto and colleagues (2010) reporting that one third of a clinical sample of CSAM users indicated symptoms of online addiction (Seto et al., 2010). Furthermore, there is evidence for a link between frequent pornography use and child sexual abuse material consumption (Seigfried-Spellar \& Rogers, 2013).

The DSM-5 (American Psychiatric Association, 2013) has defined a new category of substance-related and addictive disorders including Internet Gaming Disorder as a new research diagnosis. Internet gaming disorder has been defined as persistent or recurrent Internet use to engage in games, leading to significant impairment or distress, 
preoccupation with Internet games, withdrawal symptoms or unsuccessful attempts at control. However, due to lack of data, use of online sexual material was not included in the DSM-5 diagnoses. In the upcoming $11^{\text {th }}$ revision of the International Classification of Diseases (ICD-11) gaming disorder is to be included and defined correspondingly (World Health Organization, 2018). Further internet-related addictions will be coded in a residual category. Young has already proposed cyber sexual addiction (viewing and downloading sexual material and sexual chatting) as one of five subtypes of Internet related disorders in 1998 (Young, 1998). However, a vivid controversy has remained whether excessive online sexuality constitutes a distinct mental disorder, or whether it is only a subset of broader hypersexual tendencies with recurrent and intense sexual fantasies, sexual urges, or behaviors (Kafka, 2010). Viewing, downloading and collecting pornographic pictures and videos, usually accompanied by repeated masturbation, play the main role among sexual online activities, as the Internet has become the medium most widely used for disseminating pornographic material.

Several studies have suggested a link between addictive and deviant behavior in the Internet and adverse childhood experiences (ACE) of the adult users.

The US Centre for Disease Control and Prevention (Leeb et al., 2008) defined child maltreatment (child maltreatment and ACE are used synonymically) as "any act or series of acts of commission or omission by a parent or other caregiver that results in harm, potential for harm, or threat of harm to a child" (p. 11). Emotional abuse is described as intentional caregiver behaviour that conveys to a child that he/she is worthless or unloved; physical abuse denotes the intentional use of physical force against a child that results in or has the potential result of physical injury and sexual abuse is defined as any completed or attempted sexual contact with or exploitation of a child by the caregiver. Neglect is defined as the failure by the caregiver to provide a child's basic physical, emotional, medical or educational needs (Leeb et al., 2008).

A comprehensive review by Stoltenborgh and colleagues (2015) examined remembered child maltreatment in adult populations across the globe. The review was based on a series of meta-analyses on the prevalence of child maltreatments based on self-reports as well as informant studies. For Europe, the highest prevalence was reported for emotional (29.2\%) and physical abuse (22.9\%). Women more often reported child sexual abuse with $13.5 \%$ than men (5.6\%). Prevalence rates of physical neglect were $6.5 \%$. No rates were reported for emotional neglect (Stoltenborgh et al., 2015). In the research landscape, adverse childhood experiences have been shown to alter mental development profoundly (Gilbert et al., 2009; McElroy et al., 2016; Subic-Wrana et al., 2011; Yanos, 2010) and traumatic childhood experiences are considered a risk factor for numerous physical and psychological illnesses and behavioural problems. Associations have been found between physical abuse and somatoform disorders, emotional abuse and depression as well as personality disorders and sexual abuse and posttraumatic stress disorders (Subic-Wrana et al., 2011). Especially child sexual abuse is known as a strong risk factor for depression, anxiety disorders, addictions and sexual disorders (Gilbert et al., 2009; Levenson et al., 2016; McElroy et al., 2016; Subic-Wrana et al., 2011; Yanos, 2010) and associations have been found with the development of sexual orientation and behaviour (Görgen et al., 2012; Stroebel \& O'Keefe, 2012). However, evidence base is still limited, and causal pathways are theoretical only.

Furthermore, online as well as offline offenders have reported significantly more own experiences of sexual and physical abuse than men of the general population (Babchishin et al., 2011). Jesperson and colleagues (2009) found evidence for a sexually-abused-sexual-abuser-hypothesis in that sex offenders are more likely to have been sexually abused than non-sex offenders However, sex offenders were not more likely to have been physically abused. Differences were also found between the subgroups of sex offenders against children and adults: The latter were less likely to have been sexually abused than offenders against children, but more likely to have been physically abused (Jespersen et al., 2009).

The outpatient clinic for behavioral addictions at the department of psychosomatic medicine and psychotherapy, has offered assessment, consultation and treatment to patients suffering from Internet and gambling addiction at the University Medical Mainz, Germany, since 2008. Recently, we have seen increasing numbers of patients presenting for treatment of online sexual addiction. In 2015, the outpatient clinic for patients suffering from pedophilia was additionally launched as one of eleven sites of the prevention network "Don't offend". Since 2018 the project has been supported by the "Spitzenverband der gesetzlichen Krankenkassen" (statutory health insurance). The aim is the prevention of sexual offenses against children by anonymous and free therapeutic 
treatment for clients with pedophilia and clients with pedophilia who are at risk for online CSAM and/or direct sexual abuse of children. Therapy is anonymous and free of charge. Outpatient psychotherapy is group based and is built on: psychotherapy, sexual medicine and pharmacological therapy. (Beier et al., 2015; Beier, Ahlers, et al., 2009; Beier, Neutze, et al., 2009).

There is a lack of clinical data on online sex addiction and specifically on clinical samples requesting treatment for CSAM use. We therefore compared patients with pedophilia reporting consumption of CSAM to addictive onlinesex users and online gamers, regarding Internet use, and childhood trauma. The purpose of this study was to answer the following issues: How do patients consulting for CSAM consumption differ from those consulting for Online gaming disorders and online pornography addiction concerning a) demographic measures, b) characteristics of Internet related disorders, and c) adverse childhood experience?

We assumed that CSAM users report symptoms of Internet addiction comparable to users of online pornography and online gamers and differ significantly in terms of childhood trauma from the comparison groups.

\section{Method}

Routine data were assessed in the outpatient clinics at the department of psychosomatic medicine and psychotherapy, University Medical Center Mainz, Germany. The use of CSAM was ascertained in the intake interview by the therapist.

\section{Participants}

We included 477 consecutive patients, 357 patients consulting for addictive online gaming (OG), 63 consulting for excessive or addictive online pornography use (OP) and 57 for consumption of CSAM. Data of the CSAM consumer was collected between May 2015 and July 2018 and data of OG as well as OP users was collected between January 2014 and January 2018. As in the groups of patients consulting for excessive online pornography use and consumption of CSAM only men and in the group of gamers predominantly men contacted the clinic, only male patients were included in the samples.

In the sample of $n=57$ CSAM consumers $50.9 \%$ were classified as predominantly pedophile, $43.9 \%$ were classified as predominantly hebephile (sexual preference for the pubertal body scheme, (Beier et al., 2013) and 5.3\% with a sexual preference for the postpubertal body scheme. $N=20$ of the CSAM consumers also reported having committed contact child sexual abuse.

The samples were matched to the patients consuming child abusive material according to age. Patients younger than 18 years or older than 68 years were excluded (range: 18-68 years).

\section{Measurement}

The standardized self-report Scale for the Assessment of Internet and Computer game Addiction (AICA-S; Wölfling et al., 2011) reliably (Cronbach's $\alpha=.82$ ) assesses Internet use by 16 items. These include frequency of the main application used (online gaming, sex, etc.), time spent online (weekday/weekend), frequency of Internet use, average duration of online sessions, as well as the major DSM-5-criteria for Internet Gaming Disorder (e.g., preoccupation, loss of control, withdrawal symptoms etc.). Based on clinical validation studies (Müller, Glaesmer, et al., 2014; Müller et al., 2019) individual Internet use was categorized into non-problematic (0 to 6.5 points), misuse ( 7 to 13 points) and addictive use (13.5 points and more). The cutoffs were derived from a ROC-analysis based on a clinical sample of treatment seekers (Müller, Beutel, et al., 2014).

The Childhood Trauma Screener (CTS; Grabe et al., 2012) is a 5-item self-report inventory assessing retrospectively histories of abuse and neglect. Five types of maltreatment cover emotional, physical, and sexual abuse as well as emotional and physical neglect with one item for each type. Statements about childhood experiences (e.g., "When I was growing up, someone molested $\mathrm{me}^{\prime \prime}$ ) were rated on a 5 -point scale " $1=$ never true, 2 = rarely true, $3=$ 
sometimes true, 4 = often true, 5 = very often true". The CTS is a reliable and very economical screening instrument ( $r=0.88$, Cronbach's a =.757; Grabe et al., 2012).

\section{Procedure}

Psychological diagnoses additionally to the primary psychological concerns (either consumption of CSAM, consumption of online pornography or online gaming) were made in the initial interview by experienced clinicians. Patients contacting the prevention outpatient clinic because of consumption of CSAM were invited for an initial interview. Within the consultation of the "Don't offend" - project, a semi-structured comprehensive history regarding sociodemographic data and the person's sexual preferences was taken. Questions were guided by the DSM-IV criteria for pedophilia. Based on the Tanner stages (Marshall \& Tanner, 1969, 1970) describing the physical development of boys and girls, patients were classified according to the preferred body scheme as pedophiliac (prepubertal), hebephiliac (pubertal) or teleiophiliac (postpubertal body scheme). Furthermore, patients were interviewed about sexually motivated acts involving bodily contact with a child ("hands on") or consumption of pictures or videos (e.g., child abusive pornography). If patients were motivated they were invited for a second interview including a comprehensive SCID interview for axis I (Wittchen et al., 1997) and axis II (Fydrich et al., 1997). Patients seeking medical help in the outpatient clinic for behavioral addiction at the department of psychosomatic medicine and psychotherapy, University Medical Center Mainz, Germany were also offered a diagnostic interview. Diagnoses were made on basis of the comprehensive clinical interview.

\section{Statistical Analyses}

All analyses were conducted using SPSS version 21. To analyze group differences of scaled variables we conducted a Multivariate analysis of variance, respectively $\chi^{2}$-tests for categorical variables.

\section{Ethics}

Data on CSAM users were gathered in the prevention clinic for pedophiles with informed consent of participants, approved by the Ethics Committee of the Statutory Physician Board of Rhineland-Palatinate. These were compared to routine data of the outpatient clinic for behavioral addiction. Informed consent of the patients with scientific use of routine data was obtained prior to the first interview, as approved by the ethics committee of the Statutory Physician Board of the State of Rhineland-Palatinate.

\section{Results}

\section{Clinical and Demographic Data}

Table 1. Demographic Data of Patients Consuming Child Sexual Abuse Material (CSAM) vs. Online Pornography (OP) vs. Online Gaming (OG).

\begin{tabular}{lccc}
\hline & CSAM $(\mathbf{N}=\mathbf{5 7})$ & OP $(\mathbf{N}=\mathbf{6 3})$ & OG $^{\mathbf{1}}(\mathbf{N}=\mathbf{3 5 5})$ \\
\hline Mean age & $M=37.71(S D=11.4)$ & $M=37.5(S D=11.1)$ & $M=26.0(S D=7.7)$ \\
Partnership & $51 \%$ & $65.1 \%$ & $33.6 \%$ \\
Education & & & \\
$\quad$ High school & $50.8 \%$ & $60 \%$ & $49.9 \%$ \\
Junior high school & $15.8 \%$ & $15.9 \%$ & $14 \%$ \\
Middle school & $28.1 \%$ & $17.5 \%$ & $25.2 \%$ \\
$\quad$ No qualification/still in school & $5.3 \%$ & $3.2 \%$ & $3.7 \%$ \\
Employment & $66.7 \%$ & 80.6 & $59.1 \%$ \\
\hline Note. ${ }^{1}$ Missings: OG: $N=2$. & & &
\end{tabular}

All patients were male. The mean age of CSAM consumers was 37.71 years ( $S D=11.4$, range from 18 to 65 years). Users of online pornography were about the same age $(M=37.5$ years, $S D=11.1$, range from 21 to 68 years), and online gamers were significantly younger at an average of 26.0 years $(S D=7.7,18$ to 61 years, $F(2,474)=78.411$, 
$\left.p<.001, \eta^{2}=.25\right)$. Post-hoc tests revealed a significant difference in age between online gamers and users of online pornography as well as consumers of CSAM, but not between the latter ones. Fifty-one percent of the CSAM group reported living in a steady partnership whereas two thirds of the users of online pornography lived in a partnership (about 1/3 of online gamers). Almost half of the CSAM users and of the online gamers had completed high school whereas more than half of the users of online pornography had completed this level of education. Concerning junior high school and middle school, the distribution across the groups was similar. CSAM users had the highest percentage of "no qualification" (or "still in school") with about $5 \% .66 .7 \%$ of the CSAM users were employed, almost $80 \%$ of the users of online pornography and $59.1 \%$ of the online gamers. Clinical and demographic data is presented in Table 1.

\section{Internet Use and Its Negative Consequences}

Table 2 presents the total score and the individual items of the online addiction measure (AICA-S) including negative psychosocial consequences engendered.

Table 2. Online Addiction Criteria (AICA-S): Child Sexual Abuse Material (CSAM) vs. Online Pornography (OP) vs. Online Gaming (OG).

\begin{tabular}{|c|c|c|c|c|c|c|c|}
\hline \multirow[t]{2}{*}{ Item } & \multicolumn{2}{|c|}{$\begin{array}{l}\text { CSAM } \\
N=42\end{array}$} & \multicolumn{2}{|c|}{$\begin{array}{c}\text { OP } \\
N=61\end{array}$} & \multicolumn{2}{|c|}{$\begin{array}{c}\text { OG } \\
N=339\end{array}$} & \multirow[t]{2}{*}{ MANOVA Significance } \\
\hline & $M$ & $S D$ & $M$ & $S D$ & $M$ & $S D$ & \\
\hline Total score & 6.67 & 4.93 & 10.18 & 6.01 & 10.59 & 5.48 & $F(2,439)=9.42, p<.01, \eta^{2}=.04$ \\
\hline Hours/ week day & 4.15 & 2.93 & 4.08 & 3.07 & 6.27 & 3.72 & - \\
\hline Hours/ weekend day & 4.48 & 5.31 & 4.47 & 3.76 & 7.63 & 4.32 & - \\
\hline Preoccupation with Internet activity & 1.69 & 1.26 & 2.10 & 1.09 & 2.22 & 1.15 & $F(2,439)=3.93, p<.05, \eta^{2}=.02$ \\
\hline Online longer than intended & 2.26 & 1.25 & 2.69 & 1.19 & 2.60 & 1.18 & n.s. \\
\hline Withdrawal symptoms & 1.33 & 1.33 & 1.52 & 1.12 & 1.56 & 1.12 & n.s. \\
\hline Tolerance & 1.12 & 1.29 & 1.70 & 1.38 & 1.49 & 1.31 & n.s. \\
\hline Craving & 1.95 & 1.01 & 2.54 & 0.94 & 2.37 & 1.04 & $F(2,439)=4.27, p<.05, \eta^{2}=.02$ \\
\hline Irresistible urge & 1.48 & 1.19 & 2.26 & 1.29 & 1.96 & 1.33 & $F(2,439)=4.44, p<.05, \eta^{2}=.02$ \\
\hline Futile attempts to control & 1.36 & 1.03 & 2.39 & 1.13 & 1.73 & 1.16 & $F(2,439)=11.94, p<.001, \eta^{2}=.05$ \\
\hline Avoiding negative affect & 1.93 & 1.22 & 2.59 & 1.36 & 2.68 & 1.24 & $F(2,439)=6.69, p<.001, \eta^{2}=.03$ \\
\hline Forgetting duties & 0.95 & 1.03 & 1.85 & 1.23 & 2.14 & 1.28 & $F(2,439)=17.29, p<.001, \eta^{2}=.07$ \\
\hline \multirow[t]{2}{*}{ Loss of control } & 2.17 & 1.18 & 2.82 & 0.92 & 2.65 & 1.17 & $F(2,439)=4.34, p<.05, \eta^{2}=.02$ \\
\hline & \multicolumn{2}{|c|}{$\begin{array}{l}\text { CSAM } \\
N=57\end{array}$} & \multicolumn{2}{|c|}{$\begin{array}{c}\text { OP } \\
N=63\end{array}$} & \multicolumn{2}{|c|}{$\begin{array}{c}\text { OG } \\
N=357\end{array}$} & $\chi^{2}$-Test \\
\hline Classification (AICA-S) ${ }^{1}$ & $N$ & $\%$ & $N$ & $\%$ & $N$ & $\%$ & $\chi^{2}(4,447)=30.08, p<.001, V=.181$ \\
\hline Addiction & 6 & 10.5 & 19 & 30.2 & 107 & 30.0 & \\
\hline Misuse & 10 & 17.5 & 23 & 36.5 & 132 & 37.0 & \\
\hline No addiction & 30 & 52.6 & 21 & 33.3 & 105 & 29,4 & \\
\hline \multicolumn{8}{|l|}{ Negative consequences ${ }^{2}$} \\
\hline Problems with school/work & 6 & 15 & 36 & 59 & 251 & 73.8 & $\chi^{2}(2,441)=57.29, p<.001$ \\
\hline Problems with family/ partner & 21 & 51.2 & 51 & 82.3 & 283 & 83 & $\chi^{2}(2,444)=23.29, p<.001$ \\
\hline Financial problems & 3 & 7.5 & 18 & 29 & 116 & 34 & $\chi^{2}(2,443)=11.91, p<.05$ \\
\hline Neglecting leisure time activities & 19 & 46.3 & 42 & 67.7 & 259 & 75.7 & $\chi^{2}(2,444)=16.21, p<.001$ \\
\hline Neglecting friends & 14 & 34.1 & 47 & 75.8 & 225 & 66.2 & $\chi^{2}(2,443)=20.4, p<.001$ \\
\hline Problems with Health & 14 & 35.9 & 33 & 53.2 & 208 & 61.4 & $\chi^{2}(2,440)=9.96, p<.05$ \\
\hline
\end{tabular}

Notes. ${ }^{1}$ Classification according to AICA: $\geq 13,5$ addicted, $\geq 6.5$ misuse; Based on complete date, missings: CP: $N=11$, Online gaming: $N=13$.

${ }^{2}$ Missings: CSAM: $N=16$; OP: $N=1 ;$ OG: $N=17$.

Overall, CSAM users had the lowest total AICA-S score $\left(M=6.67, S D=4.93, F(2,339)=9.42, p<.001, \eta^{2}=.047\right)$. However, the average time using online pornography in the group of CSAM was 4.15 hours on a weekday $(S D=2.93)$ and 4.48 hours on a weekend day or holiday $(S D=5.13)$. This was almost the same for users of online pornography. The average online use was longer in online gamers during the week $(M=6.27$ hours, $S D=3.72)$ and 
even more so on weekends ( $M=7.63$ hours, $S D=4.32$ ). There was a significant difference between the groups concerning preoccupation with their online activities. The Scheffé post-hoc-test revealed a significant difference between gamers and consumers of CSAM. Concerning futile attempts at control a significant difference was found with post-hoc-tests showing significantly more attempts for users of online pornography compared to gamers and CSAM users. Furthermore, significant differences were found for craving, irresistible urge, avoiding negative affect, forgetting duties and loss of control. Post-hoc tests revealed significantly higher results for gamers and users of online pornography compared to CSAM users with an exception for irresistible urge, here only a difference between users of online pornography and CSAM users could be found in the post-hoc results. No significant differences were found regarding withdrawal symptoms, tolerance, and futile attempts at control.

Overall, CSAM users reported less frequently occurring negative consequences due to using the internet compared to users of online pornography and online gamers. The largest effect sizes indicating substantial group differences regarded decreased occupational or academic functioning (Cramer $V=.360$ ) and family conflicts (Cramer $V=.229$ ).

According to AICA-S, $10.5 \%$ of the CSAM users fulfilled criteria of addiction. $17.5 \%$ were in the misuse range, and $52.6 \%$ were classified as non-problematic Internet use (Missings: $N=11,19.3 \%$ ). In the group of users of online pornography $30.8 \%$ fulfilled criteria of addiction, $36.5 \%$ of misuse and $33.3 \%$ were in the non-problematic range. Thirty percent of the online gamers were addicted, $37 \%$ reported misuse and $29.4 \%$ showed a non-problematic use.

Negative consequences for CSAM users were most evident regarding partnership or family (51.2\%). Again, users of online pornography $(82.3 \%)$ and online gamers $(83 \%)$ reported more problems $\left(\chi^{2}(2,444)=23.29, p<.001\right.$, Cramer $V=.229)$. We found similar results concerning financial problems $\left(\chi^{2}(2,443)=11.91, p<.05\right.$, Cramer $V=.164)$, neglecting leisure time activities $\left(\chi^{2}(2,444)=16.21, p<.001\right.$, Cramer $\left.V=.191\right)$ and problems with health $\left(\chi^{2}(2,440)=9.96, p<.05\right.$; Cramer $\left.V=.151\right)$. Neglecting friends was more often reported by users of online pornography (75.8\%) compared to CSAM users (34.1\%; $\chi^{2}(2,443)=20.4, p<.001$, Cramer $\left.V=.215\right)$. See Table 2.

\section{Adverse Childhood Experiences}

Prevalence of adverse childhood experiences per group is reported in Table 3 with CSAM users reporting most frequent adverse childhood experiences on every scale except for emotional abuse.

Table 3. Prevalence (in \%) of Adverse Childhood Experiences (\%): Child Sexual Abuse Material (CSAM) vs. Online Pornography (OP) vs. Online Gaming (OG).

\begin{tabular}{|c|c|c|c|c|c|c|}
\hline \multirow{2}{*}{ Item } & \multicolumn{2}{|c|}{ CSAM $(N=56)$} & \multicolumn{2}{|c|}{ OP $(N=63)$} & \multicolumn{2}{|c|}{ OG $(N=355)$} \\
\hline & None/rarely & Often/frequently & None/rarely & Often/frequently & None/rarely & Often/frequently \\
\hline Sexual Abuse & 89.3 & 10.7 & 95.0 & 5.0 & 98.3 & 1.7 \\
\hline Physical Abuse & 83.6 & 16.4 & 87.3 & 12.7 & 90.8 & 9.2 \\
\hline Emotional Abuse & 82.9 & 17.1 & 71.4 & 28.6 & 84.8 & 15.2 \\
\hline Physical Neglect & 80.4 & 19.6 & 89.8 & 10.2 & 94.9 & 5.1 \\
\hline Emotional Neglect & 76.8 & 23.2 & 82.5 & 17.5 & 89.9 & 10.1 \\
\hline
\end{tabular}

Overall, participants reported high rates of emotional abuse and physical neglect. Online gamers reported significantly more emotional abuse than users of online pornography $(d=0.381)$ and CSAM users $(F(2,458)=5.79$, $\left.p<.05, \eta^{2}=.019, d=0.440\right)$. Further, gamers reported significantly more physical neglect $(F(2,458)=6.66, p<.001$, $\left.\eta^{2}=.030\right)$ than consumers of CSAM $(d=0.470)$. CSAM consumers reported significantly higher rates of sexual abuse $\left(F(2,458)=4.24, p<.05, \eta^{2}=.034, d=0.561\right)$ and emotional neglect $\left(F(2,458)=4.0, p<.001, \eta^{2}=.025\right.$, $d=0.442$ ) than online gamers.

Age was considered as a covariate in the analysis and showed significant results in the model $(F(5,450)=2.95$, $p<.005)$ and on the scale emotional $(F(1,450)=4.39, p<.005)$ and physical abuse $(F(1,450)=11.49, p<.001)$. By adding the covariate, the main effects on the scales emotional and sexual abuse were not significant anymore for 
the group of CSAM users, online pornography users and online gamers. Effects remained significant on the scales emotional and physical neglect. Results are presented in Table 4.

Table 4. Adverse Childhood Experiences: Child Sexual Abuse Material (CSAM) vs. Online Pornography (OP) vs. Online Gaming (OG).

\begin{tabular}{|c|c|c|c|c|c|c|c|}
\hline \multirow{2}{*}{ Item } & \multicolumn{2}{|c|}{ CSAM $(N=56)$} & \multicolumn{2}{|c|}{ OP $(N=63)$} & \multicolumn{2}{|c|}{ OG $(N=355)$} & \multirow{2}{*}{ MANOVA Significance } \\
\hline & $M$ & $S D$ & $M$ & $S D$ & $M$ & $S D$ & \\
\hline Physical Neglect & 3.92 & $1.53-$ & 4.23 & 1.21 & 4.47 & 0.93 & $F(2,458)=6.66, p<.001, \eta^{2}=.03$ \\
\hline Emotional Abuse & 3.58 & 1.28 & 3.61 & 1.11 & 4.00 & 1.05 & $F(2,458)=5.79, p<.05, \eta^{2}=.02$ \\
\hline Sexual Abuse & 1.94 & 1.26 & 1.59 & 1.06 & 1.51 & 0.97 & $F(2,458)=4.24, p<.05, \eta^{2}=.02$ \\
\hline Physical Abuse & 1.55 & 1.07 & 1.50 & 0.87 & 1.38 & 0.85 & n.s. \\
\hline Emotional Neglect & 1.34 & 0.88 & 1.18 & 0.57 & 1.07 & 0.37 & $F(2,458)=4.0, p<.001, \eta^{2}=.02$ \\
\hline
\end{tabular}

Notes. Covariate Age was significant in emotional $(F(1,450)=4.39, p<.005)$ and physical abuse $(F(1,450)=11.49, p<.001)$.

\section{Discussion}

We have described a series of patients presenting for diagnosis and treatment of the use of CSAM related to pedophilia, and we have compared them to patients presenting for addictive online pornography use and gaming from a specialized outpatient clinics for online addiction.

Patients presenting for consumption of CSAM were all male, in their middle adulthood with an average of 37.7 years. Users of online pornography had a comparable average age, whereas gamers were in their early adulthood with an average of 26 years. CSAM users, users of online sexual material and online gamers were comparably well educated. Most of the users of online pornography were employed and about $60 \%$ of the CSAM users and online gamers respectively. Approximately half of the CSAM users and users of online pornography, but only about one third of the online gamers lived in a steady partnership.

Based on a standardized self-report measure of online behavior (AICA-S), 28\% of the CSAM-consumers fulfilled criteria for misuse or addictive Internet use (vs. $66.7 \%$ of users of online pornography and $67 \%$ of online gamers). While their mean total score of online addiction was lower compared to users of online pornography and online gamers, patients reported spending an average of 4.1 to 4.5 hours per day on the Internet predominantly in pursuit of CSAM. This amounts to about half the time spent by online gamers during the week, who fulfilled the new DSM-5 criteria. Compared to users of CSAM, users of online pornography and online gamers reported higher levels of preoccupation, withdrawal symptoms, staying online longer than intended and futile attempts to control. While less frequently endorsed compared to users of online pornography and online gamers, CSAM users reported multiple negative psychosocial consequences, problems with partner or family, neglecting leisure time activities and friends as well as problems with health. These findings support our clinical impression as well as Seto and colleagues' evidence of symptoms of high rates of online addiction in CSAM users (Seto et al., 2010). A better understanding of these associations might help to identify patients with Internet addiction and establish an elaborated treatment plan including the sexual preference disorder as well as Internet addiction. However, the sample was small and the effect sizes are small to middle range, thus further research is needed to confirm our findings.

Concerning adverse childhood experiences, CSAM users reported most frequent adverse childhood experiences on every scale except for emotional abuse. Emotional abuse was reported most often by users of online pornography. Statistical analysis revealed middle range effect sizes on almost all subscales. CSAM users reported significantly more sexual abuse and emotional neglect than online gamers. However, online gamers reported significantly more emotional abuse and physical neglect compared to the CSAM users. These results are consistent with previous reports of high levels of adverse childhood experiences in the history of offenders (online and offline sexual offender (Babchishin et al., 2011; Jespersen et al., 2009). Furthermore, the results of sexual abuse in the history of CSAM users corresponded to a recent Internet survey which found that a history of childhood sexual abuse was significantly associated with child sexual offending (CSAM and sexual contact), but not with the degree of attraction to children (Bailey et al., 2016). However, results were dissolved when age was entered as a covariate. This might be explained by further studies reporting more adverse childhood experiences in the older age groups and highest rates of emotional and sexual abuse in the middle age group (Witt et al., 2017). 
We consider our findings as novel alerting us to addictive characteristics of CSAM consumption, as a considerable proportion of CSAM users have a problematic or addictive Internet use. This pathological behavior is malign as it harms children and is disruptive for family life and partnerships. As hypothesized above, a lack of emotional contact and a supportive and emotionally warm environment might be the root of behavioural problems. In the light of this notion, excessive use of CSAM might be an attempt to regulate inner conflicts and aversive emotions. In a paper on sex addiction M. D. Berry and P. D. Berry (2014) proposed that sexual addiction might be a disorder of cognitive and affective regulation. These patients show a limited capacity to identify internal states, have difficulties to differentiate between emotional states and integrate affective and cognitive states with sexual behavior (Berry \& Berry, 2014). They suggest Mentalization-based therapy (Bateman \& Fonagy, 2008, 2016) as a treatment to help the patient to understand and integrate their feelings and thoughts (M. D. Berry \& P. D. Berry, 2014).

However, we need to point out some limitations of the study. We assessed childhood maltreatment retrospectively by questionnaire. Hence, reports may be prone to bias (Glaesmer, 2016). The questions focused on abuse and neglect but other sources of adverse childhood experiences e.g., the intra-family relationships or loss of a parent, have not been included. Furthermore, in the sample of users of online pornography no comprehensive history targeting the sexual preference was made but it was asked for any consumption of CSAM. Thus, it cannot be ruled out that some of the users of online pornography also had a pedophilic sexual preference.

Furthermore, it is important to acknowledge that it is not possible to determine causation in our findings: Associations and results of high rates of adverse childhood experiences in users of CSAM may be explained by other factors (e.g., age of clients, recall bias, selection bias as more mentally ill clients contact the outpatient clinic), hence more research is needed.

\section{Conclusion}

We have found that individuals presenting for CSAM to a university-based clinic of Internet related disorders were well-educated, socially integrated and vocationally successful men in middle age. Compared to the group of gamers, scores of CSAM users on online addiction were lower, however we found evidence for addictive online behavior based on an excessive use of about 4 hours, preoccupation, withdrawal symptoms, staying online longer than intended and futile attempts to control (as recently defined by DSM-5). Excessive or addictive use of online sexual material was disruptive in almost all patients regarding social life, recreation and health.

As users of online sexual material, CSAM users spent considerable online time on weekdays and weekend days or holidays. Thus, CSAM use could be viewed as a consistent maladaptive pattern to seek stimulation. Similar to users of online sexual material it can be considered a maladaptive attempt to cope with stress, and negative affect from different sources. Furthermore, this behaviour is malign as the consumption of CSAM harms children and carries the risk of prosecution. In our study we found high rates of own experiences of childhood sexual abuse (10.7\%) and emotional neglect (23.2\%) in patients consuming CSAM. Although, it is not possible to determine causation from our results it might be interesting to pursue the hypothesis that maladaptive coping strategies may be rooted in childhood adversities, which may have compromised their coping and interpersonal capacities. Seto (2008) assumed that persons with a history of sexual abuse may grow up to use sexual contact as a coping strategy to compensate feelings of powerlessness and invalidation replicating their own abuser's behaviour. In this way, deviant or excessive sexual fantasies or activities can be understood as defenses against unpleasant emotions. In a vicious cycle, partnership or family conflict arising from excessive retreat to online consumption of pornography may further perpetuate these coping patterns. By supporting the patient in therapy to process his adverse childhood experiences, he may obtain a deeper understanding of his feelings and develop adaptive, alternative coping strategies. As mentioned above, Mentalization-based therapy might offer an effective treatment program and interventions (Bateman \& Fonagy, 2016; M. D. Berry \& P. D. Berry, 2014). Further, through therapy the patient has the opportunity of making new and supportive experiences of relationships, which might help him to develop social bonds. Social support is a protective factor against isolation, which might lead to excessive consumption of both online pornography as well as CSAM and can furthermore act as a coping strategy in emotion regulation.

In our study, approximately $5.3 \%$ of the users of CSAM $(n=57)$ predominantly had a sexual preference for adults. This finding underlines the necessity to inquire patients with excessive pornography consumption about their 
sexual preference and pornography contents precisely in order to indicate sexual offending. Obviously, not only persons with a predominantly pedophile sexual preference consume CSAM. Even if patients do not have pedophile sexual preferences, excessive pornography consumption may lead to CSAM through a striving for new and increasingly exciting material. From a conditioning perspective, sexual interest in children may be enhanced through pairing child abusive picture with sexual arousal (Prichard et al., 2013).

Currently, there is a lack of specific and validated treatments for patients consulting for consumption of CSAM. We have had good experiences with a specific group treatment program based on a treatment program by Beier, Ahlers, et al. (2009) and Beier, Neutze, et al. (2009) focusing on behavioural control, building more adaptive coping skills and social integration. It clearly supports our notion that focusing on addictive symptoms is needed for this group of patients.

Findings alert clinicians to the need to specifically inquire sexual preferences in users of online sexual material. Further research in this field is needed to develop and evaluate more specific therapeutic approaches to CSAM use taking into consideration childhood adversities.

\section{Acknowledgement}

This study has been supported by the Public Health Insurance program according to § 65d SGB V and the State of Rhineland Palatinate: Research Health care Project "Don't offend". The authors report no financial or other relationship relevant to the subject of this article.

\section{References}

Ahlers, C. J., Schaefer, G. A., Mundt, I. A., Roll, S., Englert, H., Willich, S. N., \& Beier, K. M. (2011). How unusual are the contents of paraphilias? Paraphilia-associated sexual arousal patterns in a community-based sample of men. The Journal of Sexual Medicine, 8(5), 1362-1370. https://doi.org/10.1111/j.1743-6109.2009.01597.x

American Psychiatric Association. (2013). Diagnostic and statistical manual of mental disorders: DSM-5 ${ }^{\text {TM }}$ (5th ed.). American Psychiatric Publishing, Inc.

Babchishin, K. M., Hanson, R. K., \& Hermann, C. A. (2011). The characteristics of online sex offenders: A metaanalysis. Sexual Abuse, 23(1), 92-123. https://doi.org/10.1177/1079063210370708

Bailey, M. J., Bernhard, P. A., \& Hsu, K. J. (2016). An Internet study of men sexually attracted to children: Correlates of sexual offending against children. Journal of Abnormal Psychology, 125(7), 989-1000.

https://doi.org/10.1037/abn0000213

Bateman, A., \& Fonagy, P. (2008). 8-year follow-up of patients treated for borderline personality disorder: Mentalization-based treatment versus treatment as usual. American Journal of Psychiatry, 165(5), 631-638. https://doi.org/10.1176/appi.ajp.2007.07040636

Bateman, A., \& Fonagy, P. (2016). Mentalization-based treatment for personality disorder: A practical guide. Oxford University Press.

Beier, K. M., Ahlers, C. J., Goecker, D., Neutze, J., Mundt, I. A., Hupp, E., \& Schaefer, G. A. (2009). Can pedophiles be reached for primary prevention of child sexual abuse? First results of the Berlin Prevention Project Dunkelfeld (PPD). The Journal of Forensic Psychiatry \& Psychology, 20(6), 851-867. https://doi.org/10.1080/14789940903174188

Beier, K. M., Amelung, T., Grundmann, D., \& Kuhle, L. F. (2015). Pädophilie und Hebephilie im Kontext sexuellen Kindesmissbrauchs [Pedophilia und Hebephilia in the context of child sexual abuse]. Sexuologie, 22(3-4), 127136. 
Beier, K. M., Amelung, T., Kuhle, L., Grundmann, D., Scherner, G., \& Neutze, J. (2013). Hebephilie als sexuelle Störung [Hebephilia as a sexual disorder]. Fortschritte Neurologie Psychiatrie, 81(3), 128-137.

https://doi.org/10.1055/s-0032-1330539

Beier, K. M., Neutze, J., Mundt, I. A., Ahlers, C. J., Goecker, D., Konrad, A., \& Schaefer, G. A. (2009). Encouraging self-identified pedophiles and hebephiles to seek professional help: First results of the Prevention Project Dunkelfeld (PPD). Child Abuse \& Neglect, 33(8), 545-549. https://doi.org/10.1016/j.chiabu.2009.04.002

Beier, K. M., Schaefer, G. A., Goecker, D., Neutze, J., Feelgood, S., Hupp, E., Mundt, I., Ahlers, C. J. (2006). Prävention von sexuellem Kindesmissbrauch im Dunkelfeld [Prevention of child sexual abuse in the Dunkefeld]. Sexuologie, 13(2-4), 139-147.

Berry, M. D., \& Berry, P. D. (2014). Mentalization-based therapy for sexual addiction: Foundations for a clinical model. Sexual and Relationship Therapy, 29(2), 245-260. https://doi.org/10.1080/14681994.2013.856516

Beutel, M. E., Brähler, E., Glaesmer, H., Kuss, D. J., Wölfling, K., \& Müller, K. W. (2011). Regular and problematic leisure-time Internet use in the community: Results from a German population-based survey. Cyberpsychology, Behavior, and Social Networking, 14(5), 291-296. https://doi.org/10.1089/cyber.2010.0199

Beutel, M. E., Giralt, S., Wölfling, K., Stöbel-Richter, Y., Subic-Wrana, C., Reiner, I., Tibubos, A. N., \& Brähler, E. (2017). Prevalence and determinants of online-sex use in the German population. Plos One, 12(6), Article e0176449. https://doi.org/10.1371/journal.pone.0176449

Briere, J., \& Runtz, M. (1989). University males' sexual interest in children: Predicting potential indices of "pedophilia" in a nonforensic sample. Child Abuse \& Neglect, 13(1), 65-75. https://doi.org/10.1016/01452134(89)90030-6

Bundeskriminalamt. (2016). Jahrbuch 2016 Band 4: Einzelne Straftaten/-gruppen und ausgewählte Formen der Kriminalität [Individual offenses/groups and selected forms of crime].

https://www.bka.de/DE/Aktuellelnformationen/StatistikenLagebilder/PolizeilicheKriminalstatistik/PKS2016/pks20 16_node.html

Dombert, B., Schmidt, A. F., Banse, R., Briken, P., Hoyer, J., Neutze, J., \& Osterheider, M. (2016). How common is males' self-reported sexual interest in prepubescent children? The Journal of Sex Research, 53(2), 214-223. https://doi.org/10.1080/00224499.2015.1020108

Elliott, I. A., \& Beech, A. R. (2009). Understanding online child pornography use: Applying sexual offense theory to internet offenders. Aggression and Violent Behavior, 14(3), 180-193. https://doi.org/10.1016/j.avb.2009.03.002

Fydrich, T., Renneberg, B., Schmitz, B., \& Wittchen, H.-U. (1997). SKID II. Strukturiertes Klinisches Interview für DSMIV, Achse II: Persönlichkeitsstörungen. Interviewheft. Eine deutschspeachige, erw. Bearb. d. amerikanischen Originalversion d. SKID-II von: M. B. First, R. L. Spitzer, M. Gibbon, J. B. W. Williams, L. Benjamin (Version 3/96) [SKID I. Structured clinical interview for DSM-IV. Axis I: mental disorders. Interview booklet and assessment booklet. A German-language expanded edition of the original American version of the SKID]. Hogrefe.

Gilbert, R., Spatz Widom, C., Browne, K., Fergusson, D., Webb, E., \& Janson, S. (2009). Burden and consequences of child maltreatment in high-income countries. Lancet, 373(9657), 68-81. https://doi.org/10.1016/S01406736(08)61706-7

Glaesmer, H. (2016). Assessing childhood maltreatment on the population level in Germany: Findings and methodological challenges. Child and Adolescent Psychiatry and Mental Health, 10, Article 15.

https://doi.org/10.1186/s13034-016-0104-9 
Görgen, T., Rauchert, K., \& Fisch, S. (2012). Langfristige Folgen sexuellen Missbrauchs Minderjähriger [Long-term consequences of sexual abuse of minors]. Forensische Psychiatrie, Psychologie, Kriminologie, 6(1), 3-16.

https://doi.org/10.1007/s11757-011-0129-0

Grabe, H. J., Schulz, A., Schmidt, C. O., Appel, K., Driessen, M., Wingenfeld, K., Barnow, S., Spitzer, C., John, U., Berger, K., Wersching, H., \& Freyberger, H. J. (2012). Ein Screeninginstrument für Missbrauch und Vernachlässigung in der Kindheit: der Childhood Trauma Screener (CTS). [A brief instrument for the assessment of childhood abuse and neglect: The Childhood Trauma Screener (CTS)]. Psychiatrische Praxis, 39(03), 109-115. https://doi.org/10.1055/s-0031-1298984

Hall, G. C. N., Hirschman, R., \& Oliver, L. L. (1995). Sexual arousal and arousability to pedophilic stimuli in a community sample of normal men. Behavior Therapy, 26(4), 681-694. https://doi.org/10.1016/S00057894(05)80039-5

Internet Watch Foundation. (2017). Statistics and trends 2017. https://annualreport.iwf.org.uk/\#statistics_and_trends_2017

Jespersen, A. F., Lalumière, M. L., \& Seto, M. C. (2009). Sexual abuse history among adult sex offenders and nonsex offenders: A meta-analysis. Child Abuse \& Neglect, 33(3), 179-192.

https://doi.org/10.1016/j.chiabu.2008.07.004

Kafka, M. P. (2010). Hypersexual disorder: A proposed diagnosis for DSM-V. Archives of Sexual Behavior, 39(2), 377-400. https://doi.org/10.1007/s10508-009-9574-7

Leeb, R. T., Paulozzi, L. J., Melanson, C., Simon, T. R., \& Arias, I. (2008). Child maltreatment surveillance: Uniform definitions for public health and recommended data elements (Version 1.0). Centers for Disease Control and Prevention, National Center for Injury Prevention and Control.

https://www.cdc.gov/violenceprevention/pdf/cm_surveillance-a.pdf

Levenson, J. S., Willis, G. M., \& Prescott, D. S. (2016). Adverse childhood experiences in the lives of male sex offenders: Implications for trauma-informed care. Sexual Abuse, 28(4), 340-359.

https://doi.org/10.1177/1079063214535819

Marshall, W. A., \& Tanner, J. M. (1969). Variations in pattern of pubertal changes in girls. Archives of Disease in Childhood, 44(235), 291-303. https://doi.org/10.1136/adc.44.235.291

Marshall, W. A., \& Tanner, J. M. (1970). Variations in the pattern of pubertal changes in boys. Archives of disease in childhood," 45(239), 13-23. https://doi.org/10.1136/adc.45.239.13

McElroy, E., Shevlin, M., Elklit, A., Hyland, P., Murphy, S., \& Murphy, J. (2016). Prevalence and predictors of Axis I disorders in a large sample of treatment-seeking victims of sexual abuse and incest. European Journal of Psychotraumatology, 7(1), Article 30686. https://doi.org/10.3402/ejpt.v7.30686

Müller, K. W., Beutel, M. E., Dreier, M., \& Wölfling, K. (2019). A clinical evaluation of the DSM-5 criteria for Internet Gaming Disorder and a pilot study on their applicability to further Internet-related disorders. Journal of Behavioral Addictions, 8(1), 16-24. https://doi.org/10.1556/2006.7.2018.140

Müller, K. W., Beutel, M. E., \& Wölfling, K. (2014). A contribution to the clinical characterization of Internet addiction in a sample of treatment seekers: Validity of assessment, severity of psychopathology and type of comorbidity. Comprehensive Psychiatry, 55(4), 770-777. https://doi.org/10.1016/j.comppsych.2014.01.010

Müller, K. W., Glaesmer, H., Brähler, E., Wölfling, K., \& Beutel, M. E. (2014). Internet addiction in the general population: Results from a German population-based survey. Behaviour \& Information Technology, 33(7), 757-766. https://doi.org/10.1080/0144929X.2013.810778 
National Center for Injury Prevention and Control. (2018). Child abuse and neglect.

https://www.cdc.gov/ViolencePrevention/childmaltreatment/

Niveau, G. (2010). Cyber-pedocriminality: Characteristics of a sample of Internet child pornography offenders. Child Abuse \& Neglect, 34(8), 570-575. https://doi.org/10.1016/j.chiabu.2010.01.011

Prichard, J., Spiranovic, C., Watters, P., \& Lueg, C. (2013). Young people, child pornography, and subcultural norms on the Internet. Journal of the American Society for Information Science and Technology, 64(5), 992-1000. https://doi.org/10.1002/asi.22816

Ray, J. V., Kimonis, E. R., \& Seto, M. C. (2014). Correlates and moderators of child pornography consumption in a community sample. Sexual Abuse, 26(6), 523-545. https://doi.org/10.1177/1079063213502678

Ross, M. W., Månsson, S. A., \& Daneback, K. (2012). Prevalence, severity, and correlates of problematic sexual Internet use in Swedish men and women. Archives of Sexual Behavior, 41(2), 459-466.

https://doi.org/10.1007/s10508-011-9762-0

Seigfried-Spellar, K. C., \& Rogers, M. K. (2013). Does deviant pornography use follow a Guttman-like progression? Computers in Human Behavior, 29(5), 1997-2003. https://doi.org/10.1016/j.chb.2013.04.018

Seto, M.C. (2008). Pedophilia and sexual offending against children: Theory, assessment, and intervention. American Psychological Association.

Seto, M. C., Reeves, L., \& Jung, S. (2010). Explanations given by child pornography offenders for their crimes. Journal of Sexual Aggression 16(2), 169-180. https://doi.org/10.1080/13552600903572396

Stoltenborgh, M., Bakermans-Kranenburg, M. J., Alink, L. R. A., \& van IJzendoorn, M. H. (2015). The prevalence of child maltreatment across the globe: Review of a series of meta-analyses. Child Abuse Review, 24(1), 37-50. https://doi.org/10.1002/car.2353

Stroebel, S. S., O'Keefe, S. L., Beard, K. W., Kuo, S.-Y., Swindell, S. V. S., \& Kommor, M. J. (2012). Father-daughter incest: Data from an anonymous computerized survey. Journal of Child Sexual Abuse, 21(2), 176-199.

https://doi.org/10.1080/10538712.2012.654007

Subic-Wrana, C., Tschan, R., Michal, M., Zwerenz, R., Beutel, M. E., \& Wiltink, J. (2011).

Kindheitstraumatisierungen, psychische Beschwerden und Diagnosen bei Patienten in einer psychosomatischen Universtitätsambulanz [Childhood trauma and its relation to diagnoses and psychic complaints in patients of a psychosomatic university ambulance]. Psychotherapie, Psychosomatik, Medizinische Psychologie, 61(2), 54-61. https://doi.org/10.1055/s-0030-1252047

Terminology and Semantics Interagency Working Group on Sexual Exploitation of Children. (2016). Terminology guidelines for the protection of children from sexual exploitation and sexual abuse. ECPAT International. https://www.ohchr.org/Documents/Issues/Children/SR/TerminologyGuidelines_en.pdf

Weaver, J. B., III., Weaver, S. S., Mays, D., Hopkins, G. L., Kannenberg, W., \& McBride, D. (2011). Mental- and physical-health indicators and sexually explicit media-use behavior by adults. The Journal of Sexual Medicine, 8(3), 764-772. https://doi.org/10.1111/j.1743-6109.2010.02030.x

Witt, A., Brown, R. C., Plener, P. L., Brähler, E., \& Fegert, J. M. (2017). Child maltreatment in Germany: Prevalence rates in the general population. Child and Adolescent Psychiatry and Mental Health, 11, Article 47. https://doi.org/10.1186/s13034-017-0185-0

Wittchen, H.-U., Wunderlich, U., Gruschwitz, S., \& Zaudig, M. (1997). SKID I. Strukturiertes Klinisches Interview für DSM-IV. Achse I: Psychische Störungen. Interviewheft und Beurteilungsheft. Eine deutschsprachige, erweiterte Bearb. $d$. amerikanischen Originalversion des SKID I [English translation]. Hogrefe. 
Wölfling, K., Müller, K., \& Beutel, M. (2011). Reliabilität und Validität der Skala zum Computerspielverhalten (CSVS) [Reliability and validity of the scale for the assessment of Pathological Computer Gaming (CSV-S)]. Psychotherapie, Psychosomatik, Medizinische Psychologie, 61(5), 216-224. https://doi.org/10.1055/s-0030-1263145

World Health Organization. (2018, September 14). Addictive behaviours: Gaming disorder. https://www.who.int/features/qa/gaming-disorder/en/

Wurtele, S. K., Simons, D. A., \& Moreno, T. (2014). Sexual interest in children among an online sample of men and women: Prevalence and correlates. Sexual Abuse, 26(6), 546-568. https://doi.org/10.1177/1079063213503688

Yanos, P. T., Czaja, S. J., \& Spatz Widom, C. (2010). A prospective examination of service use by abused and neglected children followed up into adulthood. Psychiatric Services, 61(8), 796-802.

https://doi.org/10.1176/ps.2010.61.8.796

Young, K., S. (1998). Internet addiction: The emergence of a new clinical disorder. CyberPsychology \& Behavior, 1(3), 237-244. https://doi.org/10.1089/cpb.1998.1.237

\section{Correspondence to:}

Caroline M. Marx

Bilhildisstraße 17

55116 Mainz

Germany

Email: marx.psychotherapie(at)gmail.com

Editorial record: First submission received on February 21, 2020. Revisions received on August 7, 2020, February 11, 2021, April 1, 2021 and April 9, 2021. Accepted for publication on April 14, 2021.

Editor in charge: David Smahel

\section{About Authors}

Dr. rer. physiol. Caroline M. Marx, Dipl.Psych. works as a psychotherapist and psychological researcher. Her main research interests regards sexual deviance, childhood maltreatment and psychodynamic aspects and theories.

Dr. rer. physiol. Kai W. Müller, Dipl.Psych., works as a psychological researcher at the Outpatient Clinic of Behavioral Addictions at the Department of Psychosomatic Medicine in Mainz, Germany. His main research interests regard behavioral addictions, particularly etiological aspects and diagnostics of Gaming Disorder and internet-related disorders.

Univ.-Prof. Dr. med. Manfred E. Beutel, Dipl. Psych., Psychoanalyst Director, Department of Psychosomatic Medicine and Psychotherapy University Medical Center Mainz, Germany. Reserach on online addiction, eHealth and psychotherapy.

(c) Author(s). The articles in Cyberpsychology: Journal of Psychosocial Research on Cyberspace are open access articles licensed under the terms of the Creative Commons BY-NC-ND 4.0 International License which permits unrestricted, non-commercial use, distribution and reproduction in any medium, provided the work is properly cited. 